\title{
Development and Optimization of a Simple and Sensitive Method for the Determination of Virginiamycin M1 Antibiotic in Aqueous Media by Capillary Electrophoresis
}

Juan Francisco Hernández-Chávez

Instituto Tecnológico de Sonora: Instituto Tecnologico de Sonora

Jesús Fernando Robles-Castro

Instituto Tecnológico de Sonora: Instituto Tecnologico de Sonora

Carlos Abraham Diaz-Quiroz ( $\nabla$ carlos.diazq@itson.edu.mx )

Instituto Tecnologico de Sonora https://orcid.org/0000-0001-9507-1589

Gabriela Ulloa-Mercado

Instituto Tecnológico de Sonora: Instituto Tecnologico de Sonora

Ramón Molina-Barrios

Instituto Tecnológico de Sonora: Instituto Tecnologico de Sonora

Pablo Gortáres-Moroyoqui

Instituto Tecnológico de Sonora: Instituto Tecnologico de Sonora

Christian Beatriz Vega-Millán

Instituto Tecnológico de Sonora: Instituto Tecnologico de Sonora

Ana Rentería-Mexía

Instituto Tecnológico de Sonora: Instituto Tecnologico de Sonora

Research Article

Keywords: Capillary electrophoresis, Wastewater, Antibiotics, Monitoring, Extraction, Quantification

Posted Date: January 27th, 2022

DOI: https://doi.org/10.21203/rs.3.rs-1229510/v1

License: (c) (1) This work is licensed under a Creative Commons Attribution 4.0 International License.

Read Full License 
${ }^{2}$ Departamento de Biotecnología y Ciencias Alimentarias,

*Corresponding author(s). E-mail(s): carlos.diazq@itson.edu.mx; 


\begin{abstract}
Virginiamycin antibiotic is used in Mexico for animal growth promotion, but has been banned in Europe due to risk of resistance development. Giving that monitoring of antibiotics is critical, the objective of this work was to develop an analytical method based on capillary electrophoresis and liquid-liquid extraction, to quantify virginiamycin antibiotic in livestock wastes. Linearity, precision, bias and extraction parameters were evaluated following ISO/IEC 17025 procedures. Method and extraction validation was satisfactorily, with average values of absolute recovery $A R=86 \%$, extraction efficiency $E E=87 \%$, and matrix effects $M E=-14 \%, R S D<15 \%$ for concentrations as low as $50 \mu \mathrm{g} / \mathrm{L}$.
\end{abstract}

\title{
1 Introduction
}

Keywords: Capillary electrophoresis, Wastewater, Antibiotics, Monitoring, Extraction, Quantification

068

069

070

071

072

073

074

075

076

077

078

079

080

081

082

083

084

085

086

087

088

089

090

091

092

Virginiamycin, an antibiotic belonging to streptogramin class, and mixture of two components: factors M1 and S1, acts individually against Micrococcus aureus and Bacillus subtilis, but in mixtures becomes highly effective against vancomycin and methicillin-resistant infections in humans, especially from Enterococcus faecium and Staphylococcus aureus (Hammerum et al, 1998).

Relevant properties and structure for M1 are depicted in Figure 1. Composed of lactone and containing pyrrolidine and oxazole rings and equal to mikamycin A, ostreogrycin A, streptogramin A and pristinamycin IIA (Goffic et al, 1977), M1 factor assembles a lipophilic, neutral, and low-degradable molecule mainly evacuated in excreta without relevant assimilation in animal tissues.

Mexico and the USA have approved virginiamycin as a feedstuff supplement, alone or combined with other agents in cattle, pig and poultry for disease prevention, increased weight growth and fodder efficiency, at doses ranging from $5 \mathrm{~g} /$ ton to $25 \mathrm{~g} /$ ton of food (Anadón and Martínez-Larrañaga, 1999). These growth promoters are administered for prolonged periods of time at 
sub-therapeutic concentrations. However, with such scheme arises an increased risk of inducing antimicrobial resistance in animal pathogens, which could colonize humans and transfer their resistance to other microorganisms (Wegener, 2003). Evidence of adverse human health consequences include infections that probably would not occur, as with fluoroquinolone-resistant Salmonella cases (Ventola, 2015). Several researchers argue that resistant infections in clinical settings have been due to migration of genetic determinants, between environmental bacteria and human pathogens (Martinez, 2009b; Wright, 2010).

Due to incorrect use of veterinary antibiotics, resistant bacteria populate the environment, animals and food products, increasing pathogen exposure and triggering human infection difficult to treat (Martinez, 2009a).

Europe banned use of virginiamycin for animal growth in 1998, due to consurveillance program (Sandegren, 2014; Bellanger et al, 2014; Bengtsson-Palme and Larsson, 2015). In fact, different studies revealed selection of resistant bac-

To quantify virginiamycin, scientists have preferred chromatography tech- 
139

140

141

142

143

144

145

146

147

148

149

150

151

152

153

154

155

156

157

158

159

160

161

162

163

164

165

166

167

168

169

170

171

172

173

174

175

176

177

178

179

180

181

182

183

184

zone electrophoresis (CZE), and (ii) micellar electrokinetic chromatography (MEKC). In MEKC, micelles and additives dissolves in the sample or background buffer (BGB) to allow massive injection and quantify without loss of resolution (Aranas et al, 2009; Wuethrich et al, 2016). To our knowledge, none CE-based method has been published or validated to quantify virginiamycin factor M1 in waste effluents (Flurer, 2001; Tobback et al, 1999). In consequence, in this work the authors developed an ease and economical MEKC method to quantify virginiamycin M1 in livestock effluents. The specific objectives were to assess the effects on analyte separation from: $\mathrm{i}$; addition of $\mathrm{NaCl}$ in samples, ii; injection time and iii; buffer composition. Method was validated according to ISO/IEC-17025 reccommendations (Magnusson, 2014).

\section{Methods}

\subsection{Reagents and Solutions}

Antibiotic standard solutions were prepared weekly using virginiamycin M1 (Sigma Aldrich, purity 95 \%, CAS 21411-53-0) with methanol (J. T. Baker) as diluent and stored at $275.15 \mathrm{~K}$. Working solutions were prepared diluting standard solutions with $\mathrm{NaCl}$ (J. T. Baker) $0.5 \%$ w/w. Background buffer (BGB) was prepared mixing quantities of sodium dodecyl sulfate solutions (SDS, CE grade), phosphoric acid $(85 \% \mathrm{w} / \mathrm{w})$, monosodium phosphate, and $\beta$-cyclodextrin (Sigma Aldrich). All solutions and samples were filtered using 0.45 um nylon filters (Millipore).

\subsection{Capillary Electrophoresis Procedures}

An MDQ P/ACE Capillary Electrophoresis System (Beckman Coulter) was used to separate samples. A capillary tube filled with the sample and BGB 
are subjected at a constant voltage and current, separating molecules at different electrophoretic velocities and read in a capillary window by a diode array detector (DAD). The analytical method is based on Micellar Electrokinetic impossible to separate by capillary zone electrophoresis (CZE). The conditions and compositions depend on analyte and capillary selected. To obtain the best

results, buffer and instrument conditions were optimized and validated using different approaches, as summarized in Figure 2.

A bare-fused silica capillary covered with polyamide (Polymicro Technololength-to-window of $50 \mathrm{~cm}$ and diameter of $50 \mu \mathrm{m}$ was used to enhance res-

in variable migration times but with no significant loss of efficiency at total

K. The instrument injects using as low as $5 \mu \mathrm{L}$ of sample volume, generally 
231 of separation efficiency was realized comparing values of the number of theo-

232

233

234

235

236

237

238

239

240

241

242

243

244

245

246

247

248

249

250

251

252

253

254

255

256

257

258

259

260

261

262

263

264

265

266

267

268

269

270

271

272

273

274

275

276

retical plates $N$, resolution $R_{s}$ and peak height $H$. While $H$ is given directly, $N$ and $R_{s}$ were calculated according to equations 1 and 2 , where $t_{m}$ stands for migration time and $w_{h}$ for peak width at half height.

$$
N=5.545\left(\frac{t_{m}}{w_{h}}\right)^{2}
$$

$$
R_{s}=\frac{t_{m 2}-t_{m 1}}{0.5 \times\left(w_{h 1}+w_{h 2}\right)}
$$

\subsection{Development of Analytical Method}

To determine the most significant factors of running buffer that affects analyte separation, an experimental design approach was chosen, as it enables lower time consumption and best data analysis. A screening method based on a $2^{4-1}$ reduced factorial design was set-up to identify the most significant buffer variables at two levels: A-pH; B-SDS; C-phosphate and D- $\beta$-cyclodextrin, as shown in Table 1. Response variables $H$ and $N$ were computed using Design Expert 7.0 software. Other variables, were optimized modifying one variable at a time with a constant running buffer. The selected variables were: $\mathrm{A}-\mathrm{NaCl}$ percent added to standard; $B$-separation voltage; $C$-injection time and $D$ cartridge temperature. Selection of the best conditions was done comparing electropherograms and peak efficiencies.

\subsection{CE Method Validation}

The CE method was validated by evaluating precision, linear range, limit of detection (LOD), limit of quantitation (LOQ) and bias. An Analysis of Variance (ANOVA) was used to compare variation within groups at 95 percent confidence. The LOD is the lowest concentration that could be detected with 
enough confidence; it was approximated by diluting a calibrator solution until signal of analyte is similar to noise, then analyzed ten times and calculated

as $L O D=3 \times S_{o}^{\prime}$, where $S_{o}^{\prime}=\frac{S}{\sqrt{n}}$ explains data disperssion. The limit of quantification $(\mathrm{LOQ})$ was then estimated as $L O D \times 5$.

To quantify virginiamycin, a linear regression of measured absorbance at constant conditions. One-factor ANOVA was run to test for variability. Repeatability limit $(r)$ was calculated as $r=2.8 \times S_{r}$. where $S_{r}$ is the standard deviation of repeatability. Intermediate precision was obtained by the precision. Then standard deviation of the repeatability $S_{r}$, was obtained by variance of the clustering factor $S_{i}$ is also obtained from the ANOVA test: $S_{i}=\sqrt{\frac{M S_{e}-M S_{i}}{n}}$. The intermediate precision $S_{I}$ was calculated by combining both terms: $S_{I}=\sqrt{S_{r}^{2}+S_{i}^{2}}$. Finally, bias was measured in relative terms 304

\subsection{Sample Treatment and Extraction Validation}


323

324

325

326

327

328

329

330

331

332

333

334

335

336

337

338

339

340

341

342

343

344

345

346

347

348

349

350

351

352

353

354

355

356

357

358

359

360

361

362

363

364

365

366

367

368

using a liquid-liquid biphasic systems as described by Díaz-Quiroz et al (2020).

Such procedure is based on the formation of an aqueous two-phase system (ATPS) comprised of citrate salt, acetonitrile and water. The system produce an organic layer rich on acetonitrile in top phase to which virginiamycin migrates. The bottom phase forms an aqueous phase rich in citrate salt, where majority of interferences are removed from the sample. For the ATPS sample clean up, a diagram phase and tie line at constant $\mathrm{pH}$ and temperature was used at an appropriate composition. Selected system was prepared at $298.15 \mathrm{~K}$ with $800 \mu \mathrm{L}$ of sample volume, $0.6 \mathrm{~g}$ of citrate salt and $150 \mu \mathrm{L}$ of acetonitrile. To form the two phases, the substances in the vials were dissolved aided by a sonication bath for $5 \mathrm{~min}$. Then, vials were centrifuged for 3 minutes and an aliquot of $10 \mu \mathrm{L}$ was transferred to a microvial. Finally, $90 \mu \mathrm{L}$ of diluent was added, vorterized and ready for injection in the CE system. Fortified samples were prepared in the same fashion, but adding antibiotics to diluent. Performance was verified using the parameters of extraction efficiency $E E$, matrix effects $M E$ and recovery $A R$, as disclosed in following equations:

$$
E E=\left(\frac{C}{B}\right)
$$

$$
M E=\left(\frac{B}{A}-1\right)
$$

$$
A R=\left(\frac{C}{A}\right)
$$

Each variable represents the peak area of virginiamycin M1 in thes conditions: $A$, in the standard solution; $B$, spiked in sample after extraction; $C$, spiked in sample before extraction. Matrix effects indicate if suppression of 
signal occurs (negative values), or if the signal has been enhanced (positive 369 values).

\section{Results}

\subsection{Method development}

Initially, the MEKC method was initiated with the injection of a standard virginiamicyn M1 solution dissolved in distilled water. A typical electropheroat $t_{m}$ around $13 \mathrm{~min}$.

Then, a factorial design was employed to determine which BGB conditions affects $H$ and $N$. The results are presented in Table 2, where $H$ and $N$ differ $\mathrm{mM}$ SDS.

Statistical information to estimate error and significance was done with 
415

416

417

418

419

420

421

422

423

424

425

426

427

428

430

431

432

433

434

435

436

437

438

439

440 441

442

443

444

445

446

447

448

450 451

452

453

454

455

456

457

458

459

460

affected by small variations of $t_{m}$ or capillary length. According to Table 3 , the model has statistical significance and $p H$ sets the main influence on response. Goodness of fit test also suggests adequate model adjustment and precision, with $A d j . R^{2}>0.8$ and $R S D<15 \%$. Regarding optimization of $\mathrm{NaCl}$ added to sample and injection volume, addition of $\mathrm{NaCl}$ from $0.1 \%$ to $1 \%$ to standard solution increased $N$ massively; as for the standard peak $N$ rises up to $7 \times 10^{5}$. In this MEKC method, online concentration was based on salt addition to samples, in a manner ionic strength scale up two to three times higher than BGB (Palmer et al, 1999). It causes an analyte sweeping at the interphase of sample plug and BGB, allowing increased sample injection without affecting negatively the analyte separation. The salt comprised $\mathrm{NaCl}$ or $\mathrm{KLi}$, enabling injection of sample plug up to $15 \mathrm{~cm}$. Interferences from samples will affect the volume injected, reducing $N$ and $H$ but in the method conditions, injection length up to $15 \mathrm{~cm}$ did not affect the separations. However, injections higher than $15 \mathrm{~cm}$ resulted in gradual peak broadening and loss of $N$. Considering typical injection in $\mathrm{CE}$ fluctuates around $1 \mathrm{~cm}$, then online concentration up to 15 folds of analyte could be attained. Finally, temperature between $295.15 \mathrm{~K}$ and $230.15 \mathrm{~K}$ and voltages between $12 \mathrm{kV}$ and $20 \mathrm{kV}$ performed satisfactorily.

\subsection{Method Validation}

Validation parameters evaluated were precision, working range, bias, $L O D$ and $L O Q$. Linear regression and goodness of fit are presented in Table 4. Working range was validated from $0.05 \mathrm{mg} / \mathrm{L}$ to $3.2 \mathrm{mg} / \mathrm{L}$. Repeatability and intermediate precision were $9.57 \%$ and $11.57 \%$ RSD respectivelty along the working range. Bias was calculated as $R \%=-8.51$ and $R S D \%=12.16$, which represent acceptable values. $L O D \approx 0.093 \mathrm{mg} / \mathrm{L}$ and $L O Q \approx 0.047 \mathrm{mg} / L$ were also estimated. 


\subsection{Extraction Validation}

Figure 5 shows an electropherogram for blank and spiked sample at $5 \mathrm{mg} / \mathrm{L}$.

As noted, not major signal suppression appears at 1:9 weight ratio dilution,

though spiked samples have to be analyzed for every run. Further, resolution

$R_{s} \geq 1.5$ seems reasonable to detect and quantify virginiamycin M1. To verify

the identity of analyte, Figure 6 shows EG's of samples fortified before and after

extraction, at $50 \mathrm{\mu g} / \mathrm{L}$ and $500 \mathrm{\mu g} / \mathrm{L}$ respectively. Virginiamycin peak appears

labeled and their vicinity is spanned in the bottom EG, showing the identity of virginiamycin unambiguously. Extraction data is presented in Table 5 for three

concentrations. The computed parameters were: $E E=0.87, M E=-0.14$ and

$A R=0.86$. Since signal suppression stand low, no significant matrix effects

reduce analyte signal. Also, average values of $E E$ and $A R$ found satisfactory,

\section{Conclusions}

Data confirms extraction of virginiamycin as an efficient process, with satisfactory recovery and minimal matrix effects at a 1:9 sample dilution ratio. The 
Table 1 Two-levels screening factorial design

\begin{tabular}{llll}
\hline Factor & $(-1)$ & $(0)$ & $(+)$ \\
\hline A: $\mathrm{pH}$ & 2 & 3 & 4 \\
B: Sodium dodecyl sulphate $^{1}$ & 35 & 50 & 70 \\
C: Sodium phosphate & 30 & 60 & 90 \\
D: $\beta$-ciclodextrin & 0 & 5 & 10
\end{tabular}

516

Except for $\mathrm{pH}$, treatment levels are concentrations expressed in $\mathrm{mM}$

${ }^{1}$ Sodium phosphate monohydrate

520

521

522

523

524

525

526

527

528

529

530

531

532

533

534

535

536

537

Table 2 Results of screening factorial design. Dependent variables, peak height $H$ and theoretical plate numbers $N$

\begin{tabular}{lllllll}
\hline Run & A & B & C & D & H & N \\
\hline 1 & 3 & 90 & 50 & 5 & 4152 & 61134 \\
2 & 4 & 120 & 70 & 10 & 2014 & 12314 \\
3 & 4 & 60 & 30 & 10 & 1661 & 5639 \\
4 & 3 & 90 & 50 & 5 & 4315 & 60415 \\
5 & 4 & 120 & 30 & 0 & 2779 & 35468 \\
6 & 3 & 90 & 50 & 5 & 3833 & 54890 \\
7 & 3 & 90 & 50 & 5 & 3476 & 46119 \\
8 & 2 & 120 & 70 & 0 & 4521 & 60757 \\
9 & 2 & 60 & 70 & 10 & 4177 & 58972 \\
10 & 2 & 60 & 30 & 0 & 5586 & 70000 \\
11 & 4 & 60 & 70 & 0 & 2430 & 27863 \\
12 & 2 & 120 & 30 & 10 & 4278 & 56884 \\
13 & 3 & 90 & 50 & 5 & 5000 & 6000 \\
\hline
\end{tabular}

538

539

540

541

542

543

544

545

546

547

548

549

550

551

552 
Table 3 ANOVA data for screening factorial design of analyte peak height $H$

\begin{tabular}{llll}
\hline Source & df & F-value & p-value \\
\hline Model & 5 & 10.97 & 0.0056 \\
A & 1 & 47.55 & 0.0005 \\
B & 1 & 0.0349 & 0.8581 \\
C & 1 & 0.6855 & 0.4394 \\
D & 1 & 5.15 & 0.0637 \\
AB & 1 & 1.41 & 0.2801 \\
Curvature & 1 & 6.56 & 0.0428 \\
Lack of Fit & 2 & 0.265 & 0.7797 \\
\hline Adeq. Precision & $R^{2}$ & Adj. $R^{2}$ & RSD\% \\
\hline 9.9766 & 0.9014 & 0.8192 & 13.38 \\
\hline
\end{tabular}

Table 4 Virginiamycin standard calibration in $\mathrm{dH} 2 \mathrm{O}$ and extract from wastewater samples. Addition of ten percent $\mathrm{v} / \mathrm{v}$ acetonitrile and 0.25 percent $\mathrm{w} / \mathrm{v} \mathrm{NaCl}$ was added to all calibrators as diluent

\begin{tabular}{lcccccccc}
\hline & \multicolumn{2}{c}{ Best-Fit Values } & & \multicolumn{2}{c}{ Std Error } & & \multicolumn{2}{c}{ Goodness of Fit } \\
\cline { 2 - 3 } Calibration & Slope & Y-intercept & & Slope & Y-intercept & & R squared & Sy.x $x^{1}$ \\
\hline$d H_{2} \mathrm{O}$ & 4075 & -109.1 & & 117.2 & 54.04 & & 0.9955 & 98.9 \\
Extract $^{2}$ & 3618 & -189.1 & & 149.53 & 86.63 & & 0.9904 & 123.86 \\
\hline
\end{tabular}

${ }^{2}$ The extract was reconstituted with diluent in a 1:9 weight ratio.

Table 5 Validation of Virginiamicyn M1 extraction using external standard calibration. Values are average of three replicates

\begin{tabular}{lll}
\hline$Y(\mu g / L)$ & $\hat{Y}(\mu g / L)$ & $R S D \times 100$ \\
\hline 50 & 44.29 & 14.39 \\
250 & 221.1 & 2.09 \\
500 & 506 & 5.96 \\
\hline
\end{tabular}


599

600

601

602

603

604

605

606

607

608

609

610

611

612

613

614

615

616

617

618

619

620

621

622

623

624

625

626

627

628

629

630

631

632

633

634

635

636

637

638

639

640

641

642

643

644

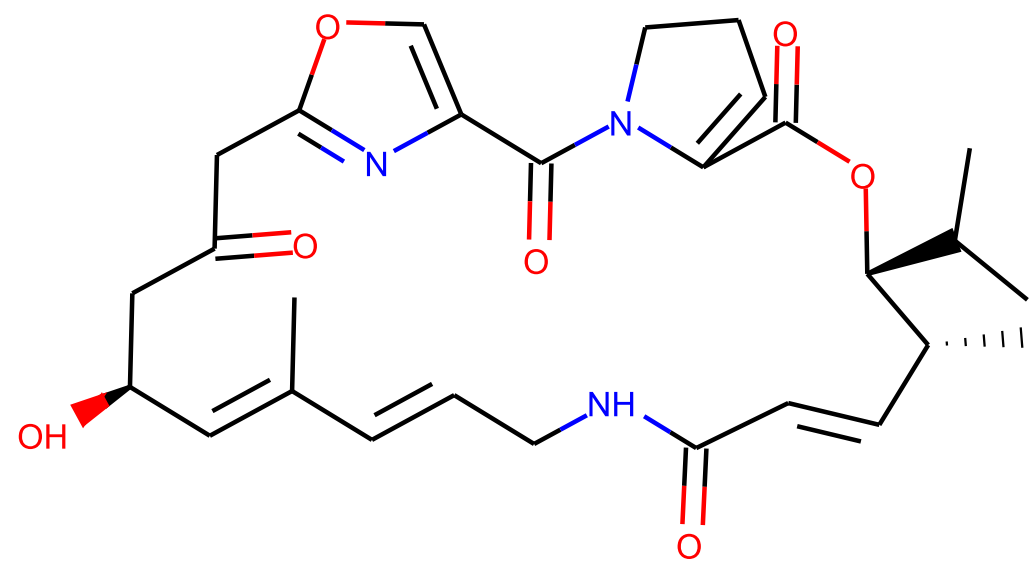

Fig. 1 Virginiamicyn M1 molecule. Relevant properties calculated by OPERA: $\log P=$ 2.49 , Solubility $=2.37 \mathrm{E}-3 \mathrm{~mol} / \mathrm{L}$, Biodegr.HalfLife $=3$ days

\section{Figures}




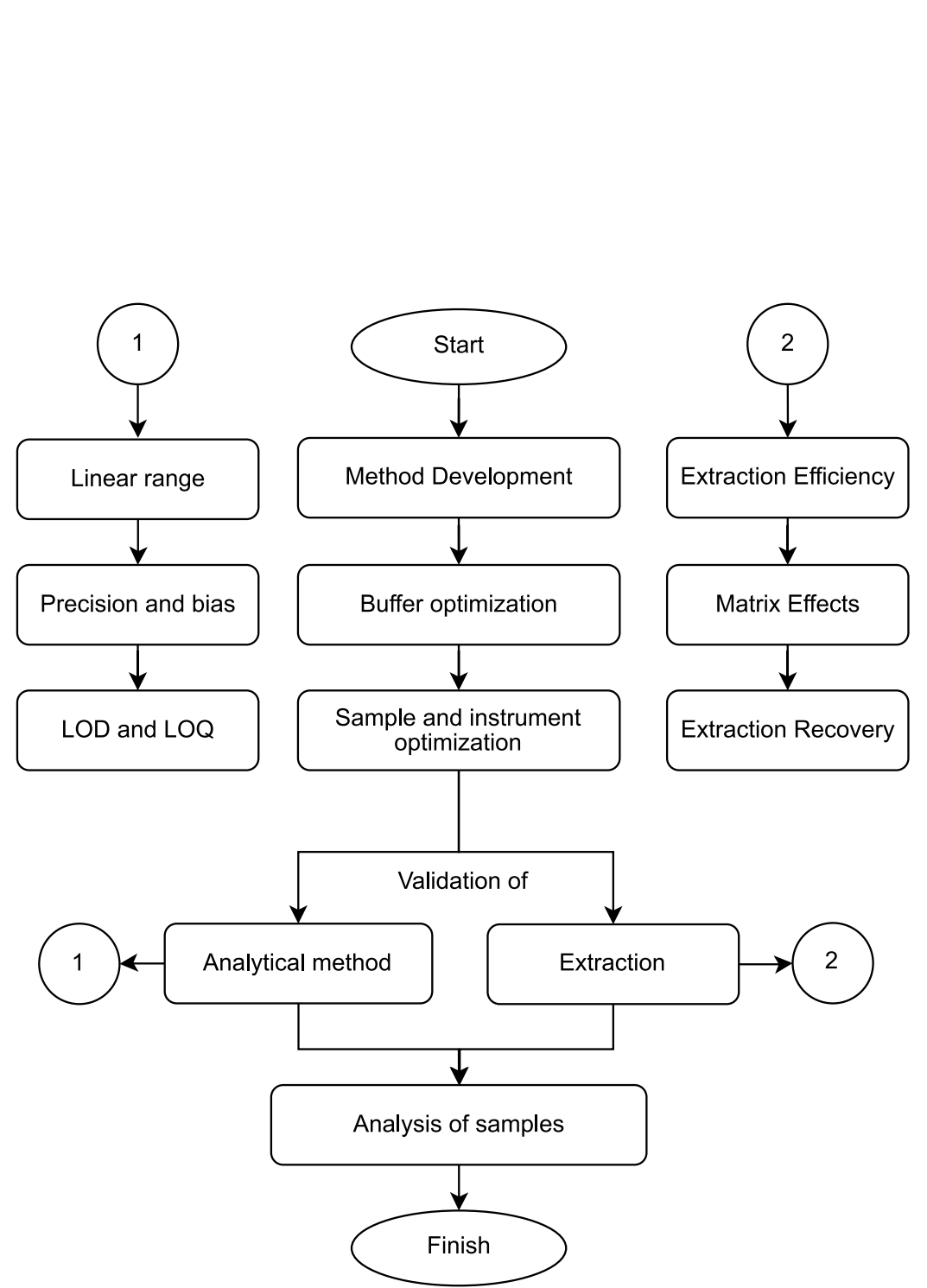

Fig. 2 Flowchart of the general method development of Virginiamycin M1 analyzed by capillary electrophoresis in porcine wastewater 
691

692

693

694

695

696

697

698

699

700

701

702

703

704

705

706

707

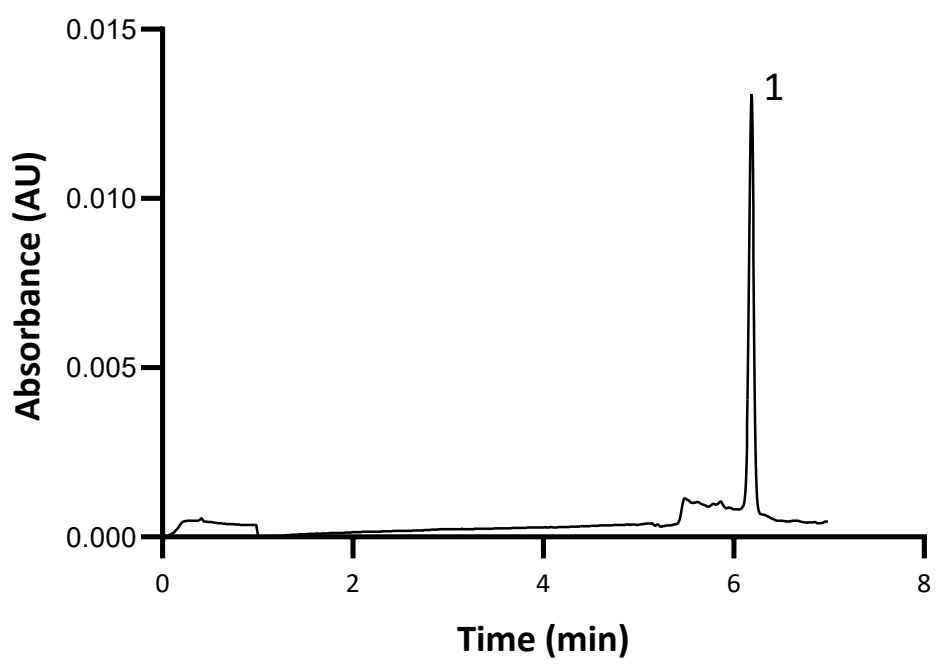

708

709

Fig. 3 Typical electropherogram of virginiamicyn (1) standard analyzed by CE-MEKC at $20 \mathrm{mg} / \mathrm{L}$. Conditions: $15 \mathrm{kV}, 25^{\circ} \mathrm{C}$, capillary $40 \mathrm{~cm}$ length and $50 \mu \mathrm{m}$ ID, reverse polarity. Sample: 0.25 percent $\mathrm{w} / \mathrm{v} \mathrm{NaCl}$ in distilled water. Buffer: SDS $35 \mathrm{mM}$, sodium phosphate

$30 \mathrm{mM}$, methanol 20 percent $\mathrm{v} / \mathrm{v}, \mathrm{pH} 2$ acidified with $\mathrm{HCl}$

712 Software: Karat 32

713

714

715

716

717

718

719

720

721

722

723

724

725

726

727

728

729

730

731

732

733

734

735

736 

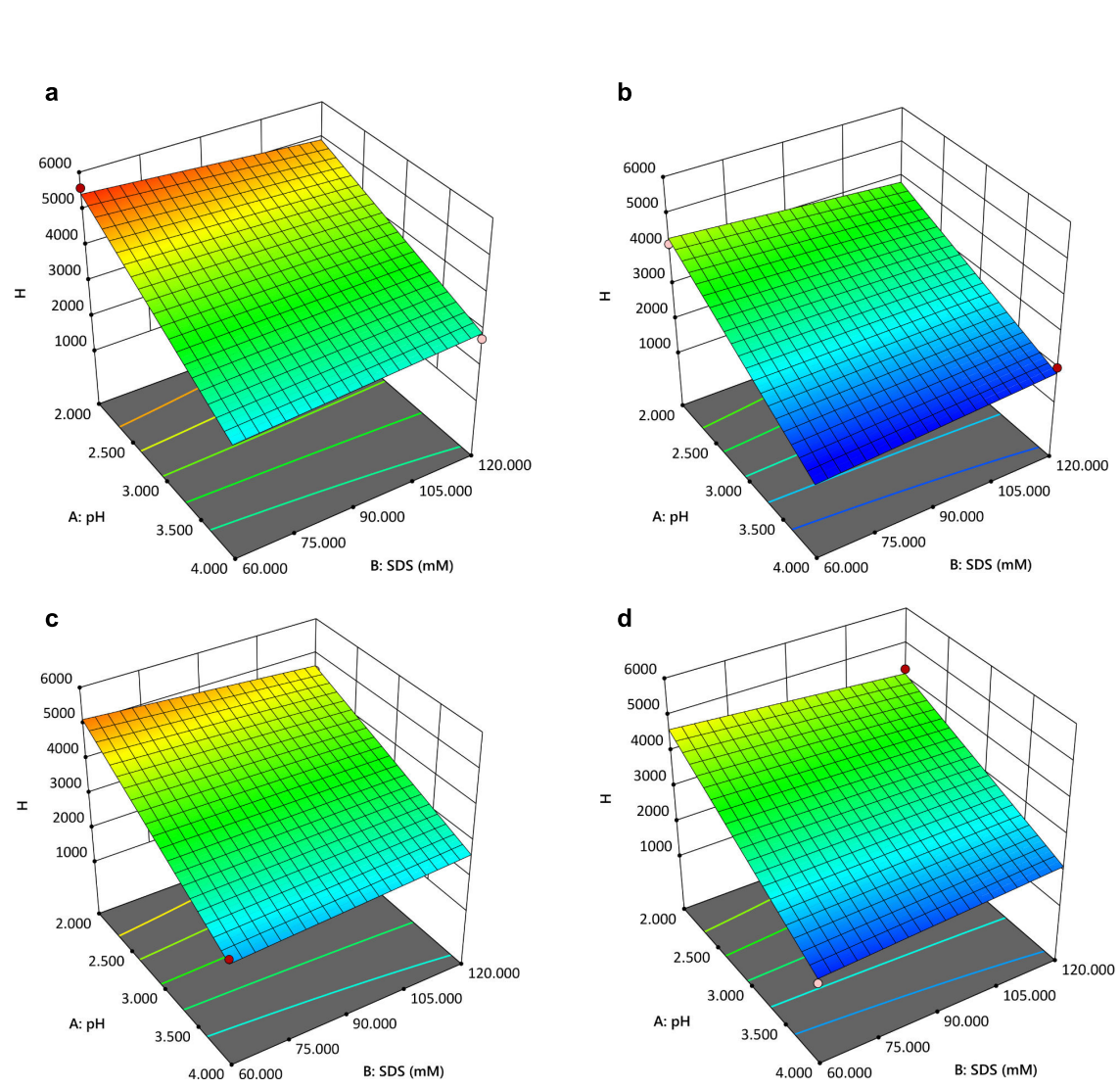

751

752

753

754

755

756

757

758

759

760

761

762

763

764

765

Fig. 4 Response surface plots for the reduced factorial design in the analysis of viginiamycin 766

M1. Independent variables are $p H$ and molar concentrations of SDS, sodium phosphate and $\beta$-cyclodextrin. Dependent variable is analyte peak height $H$. Concentrations of phosphate and cyclodextrin corresponds to following plots, coded in parenthesis: $A, 35 \mathrm{mM}$ phosphate without $\beta$-cyclodextrin $(-,-) ; B, 70 \mathrm{mM}$ phosphate and $10 \mathrm{mM} \beta$-cyclodextrin $(+,+) ; C$, $70 \mathrm{mM}$ phosphate without $\beta$-cyclodextrin $(+,-)$ and $D, 30 \mathrm{mM}$ phosphate with $10 \mathrm{mM} \beta$ cyclodextrin $(-,+)$

Software: Design-Expert 12 
783

784

785

786

787

788

789

790

791

792

793

794

795

796

797

798

799

800

801

802

803

804

805

806

807

808

809

810

811

812

813

814

815

816

817

818

819

820

821

822

823

824

825

826

827

828

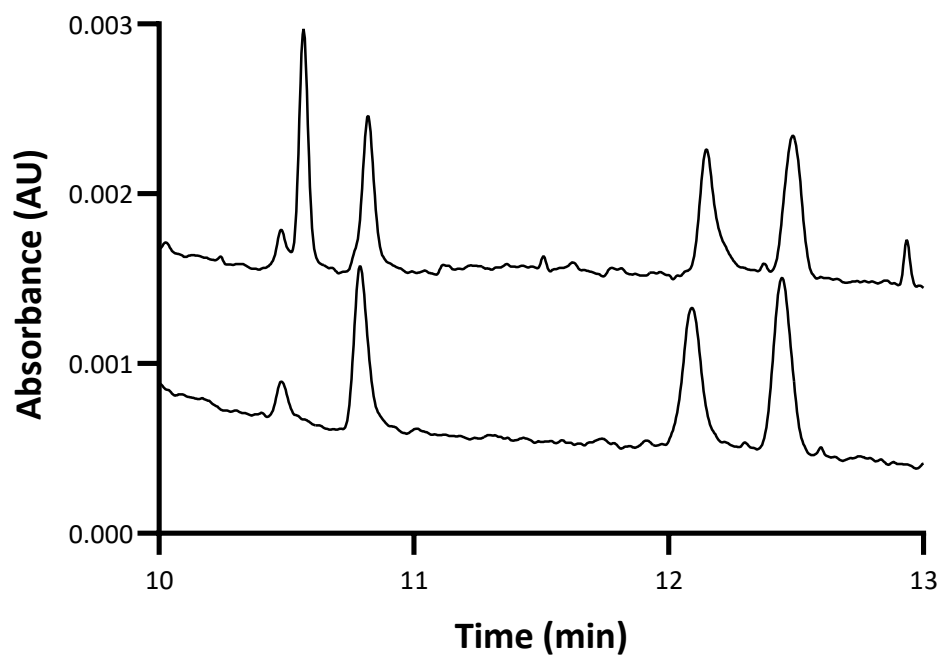

Fig. 5 Electropherogram (EG) of virginiamicyn extraction in wastewater by MEKC. Bottom EG is from a blank sample and top EG is a spike added after extraction Software: Karat 32 


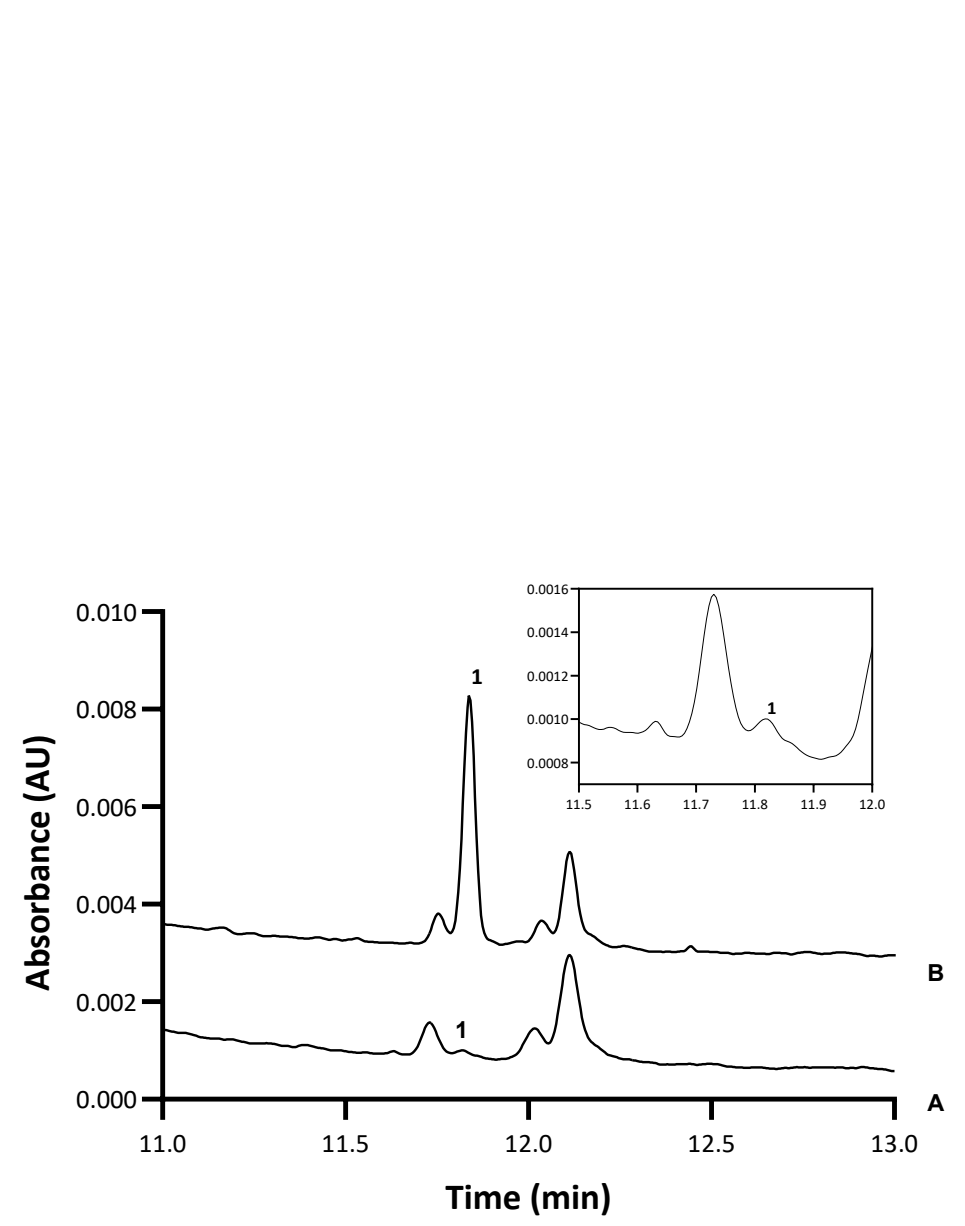

829

830

831

832

833

834

835

836

837

838

839

840

841

842

843

844

845

846

847

848

849

850

851

852

853

854

855

856

857

Fig. 6 Electropherogram (EG) of virginiamicyn (1) extraction in wastewater by MEKC. 


\section{Ethical Approval}

876

877

878

879

880

881

882

883

884

885

886

887

888

889

890

891

892

893

894

895

896

897

898

899

900

901

902

903

904

905

906

907

908

909

910

911

912

913

914

915

916

917

918

919

920

Not applicable.

\section{Consent to Participate}

Not applicable.

\section{Consent to Publish}

Not applicable.

\section{Availability of data and materials}

The data that support the findings of this study are available from the corresponding author C.Díaz-Quiroz, upon reasonable request.

\section{References}

Aarestrup FM, Seyfarth AM, Emborg HD, et al (2001) Effect of abolishment of the use of antimicrobial agents for growth promotion on occurrence of antimicrobial resistance in fecal enterococci from food animals in denmark. Antimicrob Agents Chemother 45(7):2054-9. https://doi.org/10.1128/aac. 45.7.2054-2059.2001

Anadón A, Martínez-Larrañaga MR (1999) Residues of antimicrobial drugs and feed additives in animal products: regulatory aspects. Livestock Production Science 59(2):183-198. https://doi.org/https://doi. org/10.1016/S0301-6226(99)00026-3, URL https://www.sciencedirect.com/ science/article/pii/S0301622699000263 
Aranas AT, Guidote AM, Quirino JP (2009) Sweeping and new on-line 921 sample preconcentration techniques in capillary electrophoresis. Analytical and Bioanalytical Chemistry 394(1):175-185. https://doi.org/10.1007/ s00216-009-2646-7

Bellanger X, Guilloteau H, Bonot S, et al (2014) Demonstrating plasmid928 based horizontal gene transfer in complex environmental matrices:

A practical approach for a critical review. Science of The Total Environment 493:872-882. https://doi.org/10.1016/j.scitotenv.2014.06.070,

URL http://www.scopus.com/inward/record.url?eid=2-s2.0-84903823194_ 934 partnerID $=40 \_$md $5=6 \mathrm{~b} 726 \mathrm{a} 1 \mathrm{f} 6 \mathrm{bd} 72 \mathrm{~b} 86 \mathrm{c} 4 \mathrm{e} 1 \mathrm{a} 53 \mathrm{c} 7 \mathrm{~b} 06 \mathrm{a} 6 \mathrm{a} 0$

Bengtsson-Palme J, Larsson DGJ (2015) Antibiotic resistance genes in the environment: Prioritizing risks. Nature Reviews Microbiology 13(6):396396. https://doi.org/10.1038/nrmicro3399-c1, URL http://www.scopus. 940

de Sanidad Inocuidad y Calidad Agroalimentaria SN (2016)

Lista de compuestos sujetos a monitoreo [policy brief]. 950

URL https://www.gob.mx/cms/uploads/attachment/file/128437/ 952

2-Listadodecompuestossujetosamonitoreo.pdf

Díaz-Quiroz C, Hernández-Chávez JF, Ulloa-Mercado G, et al (2020) Simul- 956 taneous extraction of antibiotic and estrogen from animal blood serum using aqueous two-phase systems as predictor of environmental impact. Environmental Science and Pollution Research 27(23):28,536-28,544

Flurer CL (2001) Analysis of antibiotics by capillary electrophoresis. Elec- 
983

984

985

986

987

988

989

990

991

992

993

994

995

996

997

998

999 1000 1001 1002 1003 1004 1005 1006 1007 Martinez JL (2009b) The role of natural environments in the evolution of 1008 1009 1010 1011

$$
\text { 22:19〈4249::AID-ELPS4249〉3.0.CO;2-8 }
$$

Goffic FL, Capmau ML, Bonnet D, et al (1977) Plasmid-mediated pristinamycin resistance. pac iia: a new enzyme which modifies pristinamycin iia. J Antibiot (Tokyo) 30(8):665-9. https://doi.org/10.7164/antibiotics.30.665

Hammerum AM, Jensen LB, Aarestrup FM (1998) Detection of the sata gene and transferability of virginiamycin resistance in enterococcus faecium from food-animals. FEMS Microbiology Letters 168(1):145-151. https:// doi.org/10.1111/j.1574-6968.1998.tb13267.x, URL https://doi.org/10.1111/ j.1574-6968.1998.tb13267.x

Hernando MD, Mezcua M, Fernández-Alba AR, et al (2006) Environmental risk assessment of pharmaceutical residues in wastewater effluents, surface waters and sediments. Talanta 69(2 SPEC. ISS.):334-342. https://doi.org/10.1016/j.talanta.2005.09.037, URL http://www.scopus. com/inward/record.url?eid=2-s2.0-31944449816_partnerID=40_md5= 29bde2a1c1549c44d22e41a8ad55b8c5

Magnusson B (2014) The fitness for purpose of analytical methods: a laboratory guide to method validation and related topics (2014)

Martinez JL (2009a) Environmental pollution by antibiotics and by antibiotic resistance determinants. Environmental Pollution 157(11):2893-2902. https://doi.org/10.1016/j.envpol.2009.05.051, URL http://www.ncbi.nlm. nih.gov/pubmed/19560847

resistance traits in pathogenic bacteria. Proceedings of the Royal Society B: Biological Sciences 276(1667):2521-2530. https://doi.org/10.1098/ 
rspb.2009.0320, URL http://www.scopus.com/inward/record.url?eid=2-s2. 0-67650486955_partnerID=40_md5=3d8ae89f50bbb502dc87fc50fa76ac97

1013

1014

1015

1016

Palmer J, Munro NJ, Landers JP (1999) A universal concept for stacking 1017 neutral analytes in micellar capillary electrophoresis. Analytical Chemistry 1018 71(9):1679-1687. https://doi.org/10.1021/ac981302a, URL https://doi.org/ $10.1021 /$ ac981302a

1019 1020 1021 1022 1023

Sandegren L (2014) Selection of antibiotic resistance at very low antibi1024 otic concentrations. Upsala Journal of Medical Sciences 119(2):103-107. https://doi.org/10.3109/03009734.2014.904457, URL http://www.scopus. com/inward/record.url?eid=2-s2.0-84900836776_partnerID=40_md5= 72eba6bb762c8a4381b08e4b178c8dc6

1025 1026 1027 1028 1029 1030 1031 1032 1033

Terabe S, Otsuka K, Ichikawa K, et al (1984) Electrokinetic separations 1034 1035 with micellar solutions and open-tubular capillaries. Analytical Chemistry 56(1):111-113. https://doi.org/10.1021/ac00265a031, URL https://doi.org/ $10.1021 / \mathrm{ac} 00265 \mathrm{a} 031$

1036 1037 1038 1039 1040

Tobback K, Li YM, Pizarro NA, et al (1999) Micellar electrokinetic capillary chromatography of macrolide antibiotics: Separation of tylosin, erythromycin and their related substances. Journal of Chromatography A $857(1-2): 313-320$

1041

1042

1043

1044

1045

1046

1047

1048

Ventola CL (2015) The antibiotic resistance crisis: part 1: causes and threats. 1049 Pharmacy and therapeutics 40(4):277

1050

1051 1052

Wegener HC (2003) Antibiotics in animal feed and their role in resis- 1053 tance development. Current Opinion in Microbiology 6(5):439-445. https: //doi.org/https://doi.org/10.1016/j.mib.2003.09.009, URL https://www. 
1059 1060

1061 1062 1063 1064 1065 1066 1067 1068 1069 1070 1071 1072 1073 1074 1075 1076 1077 1078 1079 1080 1081 1082 1083

\section{Statements and Declarations}

1085

1086 1087 1088

1089 We appreciate the financing support of Instituto Tecnológico de Sonora 1090 1091 1092 edge the scholarship 1002055 from CONACYT.

1093

1094

\subsection{Competing Interests}

1096

1097 All authors certify that they have no affiliations with or involvement in any 1098

1099 organization or entity with any financial interest or non-financial interest in 1100 1101 1102

1103

1104 


\subsection{Authors Contributions}

All authors contributed to the study conception and design. Material prepa-

ration, data collection and analysis were performed by Juan Francisco 1108

Hernández-Chávez and Jesús Fernando Robles-Castro. The first draft of the manuscript was written by Carlos Abraham Díaz-Quiroz. Gabriela Ulloa-

Mercado and Carlos Díaz contributed to original concept, funding, supplied

reagent and manuscript revisions and all authors commented on previous 